\title{
1. The genesis of inventive ideas
}

\section{SETTING THE STAGE}

The title of a book says much about the content of a book. This book is clearly about inventions, and the genesis of the specific inventions that I will discuss have taken place in U.S. federal laboratories.] To be more specific, the inventions that I discuss in this book are defined by the technology transfer mechanism known by the term "invention disclosures"- a term of art/science that I will define and discuss below-that refers to an aspect of the tangible results from inventive ideas in a federal laboratory.

However, there is more to this book than simply a heuristic and descriptive analysis of invention disclosures in U.S. federal laboratories. This book also represents an open call, and perhaps even a first step, toward understanding the genesis of the process of the transfer of new technology developed in federal laboratories to organizations in both the public and private sectors.

The overarching theme of this book aside for the moment, I realize that I am being a bit presumptuous in this opening chapter in my effort to identify, as the title of this chapter suggests, the genesis of inventive ideas. And perhaps my presumptuousness is exaggerated by the fact that I offer below thoughts about the genesis of ideas, be they good ideas or even bad ideas. I am focusing on ideas per se. I urge the reader to keep in mind that my intent for this chapter is to set the stage, or to provide a foundation or platform, for the arguments and analyses that follow in this book.

Context is always important, and the context or backdrop for thinking about the genesis of inventive ideas might be traced in the modern literature to the concept of a knowledge production function (although I make an effort below to trace the genesis of ideas further back in the history of thought). Within the discipline of economics, a starting point for a discussion about a knowledge production function - not of knowledge per se - arguably begins with how researchers have interpreted a footnote in Zvi Griliches's seminal journal article, "Issues in Assessing the Contribution of Research and Development to Productivity Growth" (Griliches, 1979).

Griliches's objective in his 1979 article was, in part, to discuss the form a production function used to describe the current level of technological knowledge observed in an economic unit (i.e., in a firm, a laboratory, a univer- 
sity, or even a country) at a specific point in time. He posited in his article that the current level of technological knowledge is functionally related to current and past levels of research and development (R\&D) expenditures in that unit. He referred to this relationship in his footnote as a knowledge production function.

Over the past four decades, a rich and creative literature has developed in the field of economics. 0 One framework to motivate a discussion about the determinants of the production of knowledge is based on the following conceptual model. At a given point in time, let $K n$ represent the existing stock of knowledge. Let $H C$ represent the available level of human capital, and let $T C$ represent the available level of technical capital. Thus, one might write:

$$
K n=F(H C, T C)
$$

Academic researchers who have estimated empirically variants of a model like the one in equation (1.1) within the context of a technology-based economic unit-generally within a private sector technology-based firm (e.g., Hall and Ziedonis, 2001; Czarnitzki, Kraft, and Thorwarth, 2009), but not always (e.g., Link, 2019; Link and Van Hasselt, 2019; Link and Oliver, 2020)-have approximated $K n$ in terms of a count of new patent applications.

The use of new patent applications (Patent Applications) as the metric to approximate the stock of knowledge, that is, technical knowledge in terms of the literature just referenced, was perhaps (likely might be a more accurate word than perhaps) driven by the availability of data to proxy new knowledge. However, there might be an alternative and perhaps more accurate approach to the measurement of $K n$ in a technology-based economic unit, and that approach could involve quantifying the existing stock of inventive ideas.

What I have in mind is that the stock of inventive ideas (Inventive Ideas), which I will define below in terms of invention disclosures as suggested above, is related to the available stock of $H C$ and $T C$ as:

$$
\text { Inventive Ideas }=f(H C, T C)
$$

where the functional form of $f(\cdot)$ in equation (1.2) is not necessarily the same as $F(\cdot)$ in equation (1.1) just above. Then, it is Inventive Ideas from equation (1.2), in the context of the extant literature, that become related to Patent Applications as:

$$
\text { Patent Applications }=G \text { (Inventive Ideas) }
$$

where the function for $\mathrm{G}(\cdot)$ is not necessarily the same as either $f(\cdot)$ or $F(\cdot)$ presented in the previous two equations.

Quite reasonably, a perceptive reader might say: "What's the big deal! All that has been shown in these three equations is that an intermediate step has been added to an already defined body of research." That perceptive reader 
would be correct ... absolutely correct. But, in my view, the intermediate step being referred to is an important step, and it is one that has been overlooked, to the best of my knowledge, in the relevant literature. From a conceptual, and perhaps from a theoretical level as well, this intermediate step emphasizes, as I discuss below, that the omnipresent human capital variable $(H C)$ is an important policy target variable along with, of course, technical capital (TC).

\section{EXPERIENCES $\rightarrow$ INVENTIVE IDEAS}

As a starting point for my endeavor to think about inventive ideas, I begin with insight of John Locke as presented in his famous treatise, An Essay Concerning Human Understanding, first published in 1690.

Locke emphasized that any and all ideas emanate from sensation or reflection. He wrote (Locke, 1690 [1996], p. 33):

Every man being conscious to himself, that he thinks, and that which his mind is employed about whilst thinking being the ideas, that are there, 'tis past doubt, that men have in their minds several ideas ... All ideas come from sensation or reflection.

With regard to "sensation or reflection," Locke went on to emphasize in his Essay that perceptions are a foundational building block of one's ideas (1690 [1996], pp. 33-4):

[O]ur senses, conversant about particular sensible objects, do convey into the mind several distinct perceptions of things, according to those various ways, wherein those objects do affect them: and thus we come by those ideas we have of yellow, white, heat, cold, soft, hard, bitter, sweet, and all those which we call sensible qualities, which when I say the senses convey into the mind, I mean, they from external objects convey into the mind what produces there those perceptions. This great source, of most of the ideas we have, depending wholly upon our senses, and derived by them to the understanding, I call SENSATION.

And Locke went even further to say (1690 [1996], p. 34):

[The] source of ideas, every man has wholly in himself: and though it be not sense, as having nothing to do with external objects; yet it is very like it, and might properly enough be called internal sense. But as I call the other sensation, so I call this REFLECTION, the ideas it affords being such only, as the mind gets by reflecting on its own operations within itself. 
Perhaps a more eloquent summary of Locke's view about experiences, and that is anticipatory of the theme of this book, is offered in the following paragraph in Essay (Locke, 1690 [1996], p. 33):

Let us then suppose the mind to be, as we say, white paper, void of all characters, without any ideas; how comes it to be furnished? Whence comes it by that vast store, which the busy and boundless fancy of man has painted on it, with an almost endless variety? Whence has it all the materials of reason and knowledge? To this I answer, in one word, from experience; in that, all our knowledge is founded; and from that it ultimately derives itself. Our observation employed either, about external sensible objects [i.e., sensations], or about the internal operations of our minds, perceived and reflected on by ourselves [i.e., reflection], is that, which supplies our understandings with all the materials of thinking. These two are the fountains of knowledge, from whence all the ideas we have, or can naturally have, do spring.

Centuries later, it was Albert Einstein who is quoted to have said: "The only source of knowledge is experience.'

Reflecting on Locke's thoughts does raise several questions, three of which are:

- Do more experiences lead to more ideas?

- Do more experiences lead to better ideas?

- Must an idea be acted on before judgment is rendered about where that idea lies on a good idea to bad idea spectrum?

Alfred Nobel is quoted to have said: "If I have a thousand ideas and only one turns out to be good, I am satisfied.' And, anticipating that many of the readers of this book will have an academic background, I am usurping three additional questions:

- How does one measure experiences?

- How does one measure ideas, inventive ideas in particular?

- Can one quantify a relationship of the form: Experiences $\rightarrow$ Inventive Ideas?

Theodore Schultz, recipient of the Nobel Memorial Prize in Economic Sciences in 1979, argued that if experiences influence one's abilities, then the economic value of one's experiences is related, at least in some part, to one's educational background (Schultz, 1975). Building on this perspective, Fritz Machlup later wrote that formal education is only one source of knowledge; knowledge is also gained experientially and at different rates by different individuals. Individuals can accrue knowledge from their day to day experiences, which "will normally induce reflection, interpretations, discoveries, and generalization ...” (Machlup, 1980, p. 179). 
Steven Johnson, the author of the New York Times bestseller Where Good Ideas Come From, set forth the following related point of view (2010, pp. 35-6):

Good ideas are not conjured out of thin air; they are built out of a collection of existing parts, the composition of which expands (and, occasionally, contracts) over time ... [T] he history of cultural progress is, almost without exception, a story of one door leading to another door, exploring the palace one room at a time.

Building, figuratively as well as literally, on Johnson's door to door metaphor, I reflect on a fact that I learned about from reading Jon Gertner's New York Times bestseller, The Idea Factory: Bell Labs and the Great Age of American Innovation. In the early 1930s, Bell Labs began to build a new research facility in Murray Hill, New Jersey, in an effort to remove itself from the hustle and bustle of New York city life. Among other things, the Murray Hill Bell Labs facility was intentionally designed to be constructed in a manner that would encourage an interchange of ideas among colleagues (2012, p. 77):

By intention, everyone would be in one another's way. Members of the technical staff would often have both laboratories and small offices - but these might be in different corridors, therefore making it necessary to walk between the two, and all but assuring a chance encounter or two with a colleague during the commute. By the same token, the long corridor of the wing that would house many of the physics researchers was intentionally made to be seven hundred feet in length. It was so long that to look down it from one end was to see the other end disappear at a vanishing point. Traveling its length without encountering a number of acquaintances, problems, diversion, and ideas would be almost impossible. Then again, that was the point. Walking down that impossibly long tiled corridor, a scientist on his [or her] way to lunch in the Murray Hill cafeteria was like a magnet rolling past iron filings [in the doors of colleagues].

Perhaps, then, a proxy for one's potential set of experiences that influence one's inventive ideas might be one's vocational and intellectual network, that is, the number of one's vocational and intellectual colleagues. This is certainly not a perfect proxy for one's set of experiences, and some readers might go further and say that this is not even a second or third best proxy. I offer no defense for it being perfect or even second best, I simply offer it, without excuse, for consideration. One of the many reasons for the imperfectness of my suggested proxy is that an individual's set of experiences predates one being active in the pursuit of one's vocation. Also, living in an information accessible environment - the information and communications technology (ICT) age as it is often called - offers an individual, regardless of one's demographics, the opportunity to gain experiences from others who might, literally speaking, not happen to be along a tiled corridor that leads to the lunch cafeteria. 
Referring back to the point above about the importance of face to face interchanges, consider the conceptual argument about experiences that has long been offered for, as an example, the establishment and ongoing operations of university science and technology parks such as Stanford Research Park in California, founded in 1951; Cornell Business and Technology Park in New York, founded in 1952; Research Triangle Park in North Carolina, founded in 1959; and the list goes on. The initial argument for the construction of such parks, and for the allocation of resources for their growth and developmentand there are many more park examples to support this claim as I, along with my co-author John Scott, have documented through our own research and writings (Link and Scott, 2003, 2006, 2007, 2012, 2013)—was that there are spillover benefits from scientists and researchers being physically close to one another. The argument is simple: tacit knowledge is more easily exchanged when scientists are in close proximity to one another.

More to this point, John Scott and I have previously pointed out (e.g., Link and Scott, 2018; Link, 2020) that there are other arguments in support of the juxtaposition of a science and technology park's scientists and researchers to one another as well as to a university's scientists and researchers, and these arguments follow directly from economic theory. These arguments, summarized below, relate to the agglomeration benefits and the sharing of knowledge that results from being in contact in a face to face manner.10

Alfred Marshall (1919) made the point, as I and others have interpreted it, that there are competitive benefits stemming from cooperation among industrial firms that are geographically close to each other. The science and technology park concept of sharing knowledge, often specialized knowledge among research-oriented firms, as well as with their host university, through proximity brings about the competitive benefits associated with ideas and even new research directions. Specifically, Marshall (1919, p. 599) wrote:

The broadest and in some respects most efficient forms of cooperation are seen in a great industrial district where numerous specialized branches of industry have been welded almost automatically into an organic whole.

Also, cluster theory, as interpreted by for example Paul Westhead and Stephen Batstone (1998), predicts that the process of creating innovations is more efficient because of experiential knowledge spillovers, enhanced benefits, and lower costs that result from the clusters of research and technology-based firms being near a university. Barriers to tacit knowledge, search costs, and acquisition costs are all reduced when economic units participate with one another in a cluster-like environment. In other words, clustering engenders a two-way or reciprocal flow of scientific knowledge. As a result, it is perhaps not surprising that, as I along with John Scott (e.g., Link and Scott, 2003) found 
from our survey-based research of university provosts, universities are able to attribute more publications and patents, greater success getting extramural funding, improved placement of doctoral graduates, and an enhanced ability to hire preeminent scholars to having a science and technology park physically located on their campuses (if not on their campuses, then very close by).

In addition to the benefits of firms clustering together within a park, the issue of the proximity of a park to its university, that is, the clustering of firm scientists and researchers with university scientists and researchers, might also influence the success of the park. Kelsi Hobbs, John Scott, and I, through our empirical endeavors (Link and Scott, 2006; Hobbs, Link, and Scott, 2017a, 2017b), have shown that the growth of employees over time in university science and technology parks increases the more closely the park is located to the university campus. This empirical finding should perhaps not be an unexpected one given the arguments I have summarized just above.

The list of agglomeration examples goes on. As David Audretsch (1998, p. 21) noted, although not with respect to science and technology parks: "[Tacit] knowledge ... is best transmitted via face to face interaction and through frequent and repeated contact." And along those same lines of thought, Edward Glaeser and colleagues (1992, p. 1126) pointed out, although also not with respect to science and technology parks: "Intellectual breakthroughs must cross hallways and streets more easily than oceans and continents."

Referring again to the relationship between employment growth and proximity of a science and technology park to its host university, the relationship ceases to be observed in the data beginning with the new millennium (year 2000) during which time the ICT revolution is said to have begun and then rapidly accelerated. Simply, face to face interactions could and did occur electronically and at a much lower cost than physical face to face interactions. As Kelsi Hobbs, John Scott, and I wrote (2017a, p. 503): "[T]he ICT revolution mitigated aspects of the need for scientists to have face to face interactions with university scientists ..." Even after the ICT revolution began and its effects were part of everyday life, it is still experiences gained, although using a technology-based medium of exchange, that matter for the development of and nurturing of creative ideas.

Finally, path dependency theory, as embraced through the scholarship of for example Paul David (1985), predicts that for technologies spawned by ideas generated in a university, creating a science and technology park (from the perspective of the university) and locating in the park (from the perspective of firms) give positive reinforcing feedback to both parties to continue their particular scientific development paths for the development of a particular technology. A university's science and technology park can be said to reinforce path dependence that locks in the success for the technology developed 
in the park that relies on the ideas of university scientists and researchers (Link and Scott, 2018).

Thus, the foundation for the following chapters in this book is that the genesis of inventive ideas is related to one's experiences, and one's experiences are richer when (1) interacting among as well as conducting research among groups of colleagues rather than in isolation, and when (2) having appropriate complementary resources.12 This relationship network forms the basis of the arguments and analyses that are presented in the chapters in the rest of this book under the rubric of what I am calling the Experiences $\rightarrow$ Inventive Ideas paradigm.

\section{THE CHAPTERS THAT FOLLOW}

The remainder of this book is outlined as follows. In Chapter 2, I define what I mean by the term Inventive Ideas. That is, I define Inventive Ideas to be reflected in, and thus measured in terms of, the number of new invention disclosures in a federal laboratory. While the invention disclosures that I study below are those that originate from scientists and researchers in federal laboratories, the concept of invention disclosures nevertheless goes beyond the boundaries of a federal laboratory as I will discuss below. In part, my focus on federal laboratories is not only driven by data availability, as I stated in an endnote to this chapter, but also it is driven by a conspicuous void of empirical research on elements of technology transfer in federal laboratories (although published research efforts by John Scott and me, as well as others, are slowly beginning to fill that void) $\mathrm{H}^{3}$

Federal laboratories have long been an important technology-based infrastructure, as well as an institutional platform, in the United States. For example, the development of the Manhattan Project at the Los Alamos National Laboratory ${ }^{13}$ is no doubt remembered by many around the world. Jumping ahead in time, President Jimmy Carter-in his October 1979 address to the U.S. Senate Committee on Commerce, Science, and Transportation and the Select Committee on Small Business; and to the U.S. House of Representatives Committee on Science and Technology and the Committee on Small Business - set forth a number of policy initiatives to address the productivity slowdown that was plaguing the U.S. economy during the time period of the 1970s (and the productivity slowdown will be discussed in Chapter 2). In President Carter's address, he pointed out the importance of "the transfer of knowledge from Federal laboratories" (Carter, 1979, p. 64) for helping to "ensure our country's continued role as the world leader in industrial innovation” (p. 63). 
Technology transfer from federal laboratories was also emphasized in U.S. Technology Policy, issued by President George H.W. Bush in 1990 (Executive Office of the President, 1990, pp. 1-6):

Government policies can help establish a favorable environment for private industry [by improving] the transfer of Federal laboratories' R\&D results to the private sector [and by expediting] the diffusion of the results of Federally-conducted R\&D to industry, including licensing of inventions ...

Federal laboratories were more recently highlighted, in terms of the national importance of technology transfer, by President Barack Obama. In his October 2011 Presidential Memorandum-Accelerating Technology Transfer and Commercialization of Federal Research in Support of High-Growth Businesses-President Obama wrote (Obama, 2011):17

Innovation fuels economic growth, the creation of new industries, companies, jobs, products and services, and the global competitiveness of U.S. industries. One driver of successful innovation is technology transfer, in which the private sector adapts Federal research for use in the marketplace . . . I direct that [Federal laboratories] establish goals and measure performance, streamline administrative processes, and facilitate local and regional partnerships in order to accelerate technology transfer and support private sector commercialization.

President Donald Trump, in his The President's Management Agenda (Trump, undated, p. 47), set forth the goal to: "Improve the transfer of technology from federally funded research and development to the private sector to promote U.S. economic growth and national security" for modernizing government for the 21 st century. 5 Specifically, he wrote (p. 47):

For America to maintain its position as the leader in global innovation, bring products to market more quickly, grow the economy, and maintain a strong national security innovation base, it is essential to optimize technology transfer and support programs to increase the return on investment (ROI) from federally funded R\&D.

In Chapter 2, I will also describe trends over time in invention disclosures, aggregated from federal laboratories to the agency level. These trends, across federal agencies, show that invention disclosures have not been increasing over time, and in fact in several agencies they have even been decreasing. If new inventive ideas do not increase over time, might the relevance of scientific ideas that ultimately stem from public investments in scientific and technical research in federal laboratories stagnate? I will revisit this question a number of times throughout this book. In my view, the decline in the number of invention disclosures, or the non-increase in invention disclosures, is worrisome 
because it signals a decline in new scientific ideas. And, based on what I have written above, many writers think that ideas beget ideas.

More to the point, we know from the scholarly writings of James Burke (1978) that inventions are linked. And inventions are the product of inventive ideas. If the growth of inventive ideas stagnates, from where will future inventions come? If the growth of future inventions stagnates, will technological advancement do the same?

In Chapter 3, I will present empirical evidence that suggests that an Experiences $\rightarrow$ Inventive Ideas paradigm has construct validity across federal agencies - a federal agency, the aggregation unit of its federal laboratories, being the data-specific focus of this book. I quantify Experiences in terms of the number of STEM (Science, Technology, Engineering, and Mathematics) colleagues with whom scientists and researchers interact in the federal laboratories. My empirical analyses in this chapter show that in some federal agencies the Experiences $\rightarrow$ Inventive Ideas relationship, so measured, is stronger (in a statistical sense) than in others. This chapter concludes with the interpretative question as to why some agencies are more efficient in the process of creating new inventive ideas, that is: Why are some agencies more efficient in an Experiences $\rightarrow$ Inventive Ideas process than others?

In Chapter 4, I will offer a conceptual as well as empirical answer to the question about why some agencies are more efficient in the process of creating new inventive ideas. The answer, as the reader might already expect, is that the scientists and researchers in some agencies have more technical capital, that is more R\&D (research and development) resources, with which to work, than do the scientists and researchers in other agencies. This chapter concludes with affirmation of the relationship in equation (1.2) above: Inventive Ideas $=$ $f(H C, T C)$. And I posit that this relationship may be closer to the knowledge production function than what has been reported in the literature, which was spawned by Zvi Griliches's 1979 seminal paper. The knowledge production function that is often estimated in the academic literature is described mathematically in the appendix at the end of this chapter.

In Chapter 5, I will add to the extant literature through empirical analyses of what I call an enhanced knowledge production function. Specifically, I offer evidence in support of the statistical significance of the relationship: Patent Applications $=G$ (Inventive Ideas). And I will posit that this relationship has policy relevance. If patent applications are a first step through which new scientific knowledge is formally developed in federal laboratories so that it can eventually be transferred to society through licensed patented inventions, and if such enhanced technology transfer is a national policy goal-which President Obama's Memorandum and President Trump's Agenda cited above clearly suggest that it is - then inventive ideas are a relevant national policy target variable. 
In Chapter 6, I will present a case study of the Patent Applications $=G$ (Inventive Ideas) relationship using invention disclosures information from one federal laboratory: the National Institute of Standards and Technology (NIST) within the U.S. Department of Commerce.

In Chapter 7, I will depart a bit from a focus on patent applications as a relevant technology transfer mechanism, and examine another technology transfer mechanism, namely cooperative research and development agreement (CRADA) activities. The relationship that I explore in this chapter is CRADAs $=G$ (Inventive Ideas). I couch the non-significant statistical findings in this chapter in the context of the economic concepts of market failure and government failure.

Finally, in Chapter 8, I will offer a brief summary of the findings presented in this book. I also expand on policy recommendations for enhancement of scientific ideas with particular reference to President Trump's The President's Management Agenda, and I suggest a future research agenda that emphasizes not only unexplored technology transfer activities in federal laboratories, but also other areas of research related to an Experiences $\rightarrow$ Inventive Ideas paradigm.

\section{APPENDIX ON KNOWLEDGE PRODUCTION FUNCTIONS}

The general form for an estimable knowledge production function is, following Hall and Ziedonis (2001) and Czarnitski, Kraft, and Thorwarth (2009):

$$
\text { PatApp }=A R D^{\alpha} L^{\beta}
$$

where PatApp is the count of new patent applications, A is a constant or disembodied shift factor, $R D$ represents $\mathrm{R} \& \mathrm{D}$ investments, $L$ represents the number of employees, and $\alpha$ and $\beta$ measure the contribution of each input to the production of patent applications.

Equation (A.1) can be rewritten in two ways. Taking the natural logarithm in equation (A.1) yields:

$$
\log (\text { PatApp })=\log (A)+(\alpha+\beta+\gamma) \log (L)+\alpha \log (R D / L)
$$

Alternatively, equation (A.1) itself can be rewritten as:

$$
\text { PatApp }=\exp (\log (A)+(\alpha+\beta+\gamma) \log (L)+\alpha \log (R D / L))
$$

Equations (A.2) and (A.3) represent the traditional framework for the estimation of a public sector knowledge production function. More generally, the production function for patent applications may be unknown, so that estimating equations such as (A.2) and (A.3) cannot be derived. In this case, it may be of interest to estimate a semi- or non-parametric regression model for patent applications. 
Equation (A.2) is often estimated by an Ordinary Least Squares (OLS) regression, using those observations for which the logarithms are well defined. Equation (A.3) is often estimated by a Poisson or negative binomial regression.

In addition to the research by Hall and Ziedonis (2001) and Czarnitski, Kraft, and Thorwarth (2009), see Link, Morris, and Van Hasselt (2019), Link and Van Hasselt (2019), Link (2019), and Link and Oliver (2020).

\section{NOTES}

11. According to U.S. Code, Title 15 (Chapter 63, § 3703): "Federal laboratory means any laboratory, any federally funded research and development center, or any center ... that is owned, leased, or otherwise used by a Federal agency and funded by the Federal Government, whether operated by the Government or by a contractor ... Federal agency means any executive agency ... as well as any agency of the legislative branch of the Federal Government." The phrase "national laboratories" refers to mission-driven research centers, and they are generally federally funded research and development centers (FFRDCs) or Government Owned, Contractor Operated (GOCO) laboratories. "Contractor operated labs ... operate facilities and equipment that are owned by the federal government, but the staff is employed by a private or nonprofit contractor that operates the lab under a contract with the federal government" (GAO, 2018, p. 10). The phrase "federal laboratories" refers to Government Owned, Government Operated (GOGO) laboratories. "Government operated labs are usually owned or leased by the federal government and are predominantly staffed by federal employees" (GAO, 2018, p. 10). There are different estimates of the number of federal laboratories in the United States. One lower bound estimate comes from the Federal Laboratory Consortium (FLC), which counts as its members more than 300 federal laboratories (FLC, 2017).

2. There may also be a related literature by philosophers who write about epistemology. I yield to these scholars to present that important body of thought.

3. I confess that data availability was in fact a factor in the knowledge production studies in which I was involved (e.g., Link, 2019; Link and Van Hasselt, 2019; Link, Morris, and Van Hasselt, 2019; and Link and Oliver, 2020).

4. This discussion about John Locke draws from Audretsch and Link (2019).

5. See https://ww.Brainyquote.com/quotes/albert_einstein_148788 (accessed July 3, 2020).

6. See https://en.wikiquote.org/wiki/Alfred_Nobel (accessed July 3, 2020).

7. An important point. I am using the symbol $\rightarrow$ throughout this book as a shorthand for the phrase is related to. I will use this symbol many times in later chapters to refer to how I suggest one interprets selected regression results. I am not using this $\rightarrow$ symbol to emphasize a causal relationship, although the relationships that I estimate, and which are described in Figure 2.2 in the following Chapter 2, do suggest causality in terms of the technology transfer process in federal laboratories.

8. I discuss, along with Dennis Leyden (Leyden and Link, 2015), this concept of experience in terms of networks, specifically weak ties and strong ties within an entrepreneur's or entrepreneurial firm's social network. See also Acemoglu, Akcigit, and Kerr (2016, p. 11483) who write about, although in the context of patents, the importance of networks in the following way: "Technological and scientific progress propels economic growth and long-term well-being. Prominent 
theories depict this process as a cumulative one in which new innovations build on past achievements, using Newton's descriptive phrase of 'standing on the shoulders of giants.' $\ldots$ [T]he idea that when there is more past innovation for a particular technology class to build on, then that technology class innovates more."

9. Caveats aside, I now formally invoke the usual disclaimer that the proxy for experiences that I am suggesting is the best measure for a set of one's experiences that is available to me within the realm of technology transfer mechanisms, metrics, and related activities in federal laboratories. In a very specific sense, the availability of data is driving my arguments here, as I suspect it has with others who have studied the technology transfer process in federal laboratories, as well as driving the analyses that I present in the following chapters of this book.

10. The following section draws from Link and Scott (2018) and Link (2020).

11. In other words, the new millennium and the ICT revolution presented both challenges and opportunities regarding employment growth and the proximity of a science and technology park.

12. On a related note, and drawing from scholars in the field of geography, Ballard, Jara-Figueroa, Petralia, Steijn, Rigby, and Hidalgo (2020, p. 8) offer the following argument for why complex ideas concentrate in big cities. They write: "We argue that complex economic activities tend to be more concentrated in large urban areas because they require a deeper division of knowledge and labor. This also tells us that much of the (tacit) knowledge needed to perform these activities is embodied in social networks and that does not travel well through digital communication channels." I believe that this idea complements the agglomeration benefits noted above to the extent that the number of one's research colleagues proxies the complexity of ideas with which one is surrounded. It also underscores my emphasis on Experiences.

13. Zack Oliver and I (Link and Oliver, 2020) have offered a strong argument that data availability is the culprit that has limited studies of technology transfer in federal laboratories in both the United States and elsewhere. Relevant literature reviews are presented in Link and Oliver (2020) and, to a more limited extent, in Bozeman (2000). See also endnote 9 above.

14. See https://www.history.com/topics/world-war-ii/atomic-bomb-history\#section_2 (accessed July 3, 2020).

15. See https://www.lanl.gov/ (accessed July 3, 2020).

16. According to the Bureau of Labor Statistics (BLS): "[P]roductivity growth has the potential to lead to improved living standards for those participating in an economy, in the form of higher income, greater leisure time, or a mixture of both. With gains in labor productivity, an economy is able to produce increasingly more goods and services for a given number of hours of work. These gains in efficiency make it possible for an economy to achieve growth in labor income, profits and capital gains of businesses, and public sector revenue. Moreover, as labor productivity grows, it may be possible for all of these factors to increase simultaneously, without gains in one coming at the cost of one of the others." See https://www .bls.gov/opub/btn/volume-6/below-trend-the-us-productivity-slowdown-since-the -great-recession.htm (accessed July, 2020).

17. In fact, it is my view that President Obama's Memorandum was the salvo to initiate others to pay closer research attention to technology transfer activity in federal laboratories. See, for example, the RTI International study, commissioned by the National Institute of Standard and Technology (NIST), conducted by Link, 
Oliver, Jordan, and Hayter (2019). Also, the Board on Science and Technology Policy at the National Academies (the National Academy of Sciences, the National Academy of Engineering, and the Institute of Medicine) recently commissioned a study on Advancing Commercialization from the Federal Laboratories (see https://sites.nationalacademies.org/PGA/step/PGA_191994, accessed July 3, 2020).

18. I will elaborate on the policy importance of President Trump's The President's Management Agenda in Chapter 8. 